\title{
Nanoparticles functionalised with an anti-platelet human antibody for in vivo detection of atherosclerotic plaque by magnetic resonance
} imaging

\author{
Marie-Josée Jacobin-Valat ${ }^{\mathrm{ab} 1}$, Jeanny Laroche-Traineau ${ }^{\mathrm{ab} 1}$, Mélusine Larivière ${ }^{\mathrm{ab}}$, Stéphane Mornet ${ }^{\mathrm{c}}$, \\ Stéphane Sanchez ${ }^{\mathrm{ab}}$, Marc BiranPhDa, Caroline Lebaron ${ }^{\mathrm{d}}$, Julien Boudon PhD ${ }^{\mathrm{c}}$, Sabrina Lacomme ${ }^{\mathrm{e}}$, \\ Martine Cérutti ${ }^{d}$, Gisèle Clofent-Sanchez ${ }^{\text {ab }}$ \\ a CNRS, UMR5536, CRMSB, Centre de Résonance Magnétique des Systèmes Biologiques, Université Bordeaux, Bordeaux, France \\ b Plateforme Technologique et d'Innovation Biomédicale, Pessac, France \\ 'CNRS, UPR9048, Université de Bordeaux, Institut de Chimie de la Matière Condensée de Bordeaux, Pessac, France \\ "CNRS, UPS3044, "Baculovirus et thérapie", St Christol-Les-Alez, France \\ e Bordeaux Imaging Center, Université Bordeaux, Bordeaux, France \\ ${ }^{1}$ Contributed equally to this work.
}

Corresponding author at: CNRS, UMR5536, CRMSB, Centre de Résonance Magnétique des systèmes Biologiques, Université Bordeaux, Bordeaux, France. gisele.clofent-sanchez@rmsb.u-bordeaux2.fr

Sources of funding: This study was supported by two public grants from the French "Agence Nationale de la Recherche" within the context of the Investments for the Future Program, referenced ANR-10-LABX-0057, named IdEx and TRAIL MIMATHUMAB and by public grants from the French "Agence Nationale de la Recherche" within the context of PCV programme, named IMATHABIO and SVSE5 programme, named ATHERANOS.

From the Clinical Editor: Current clinical assessment of atherosclerotic plagues is suboptimal. The authors in the article designed functionalized superparamagnetic iron oxide nanoparticles with TEG4, a recombinant human antibody, to target activated platelets. By using MRI, these nanoparticles can be utilized to study the process of atheroma pathogenesis.

Key words: MRI contrast agents ; Atherosclerosis ; Nanoparticles ; Platelets ; Human antibody

Abstract: Atherosclerosis is an inflammatory disease associated with the formation of atheroma plaques likely to rupture in which platelets are involved both in atherogenesis and atherothrombosis. The rupture is linked to the molecular composition of vulnerable plaques, causing acute cardiovascular events. In this study we propose an original targeted contrast agent for molecular imaging of atherosclerosis. Versatile USPIO (VUSPIO) nanoparticles, enhancing contrast in MR imaging, were functionalised with a recombinant human IgG4 antibody, rlgG4 TEG4, targeting human activated platelets. The maintenance of immunoreactivity of the targeted VUSPIO against platelets was confirmed in vitro by flow cytometry, transmission electronic and optical microscopy. In the atherosclerotic $\mathrm{ApoE}^{-/-}$mouse model, high-resolution ex vivo MRI demonstrated the selective binding of TEG4-VUSPIO on atheroma plaques. It is noteworthy that the rationale for targeting platelets within atherosclerotic lesions is highlighted by our targeted contrast agent using a human anti- $\alpha$ llb $\beta 3$ antibody as a targeting moiety.

Atherosclerosis is a systemic disorder affecting arterial beds throughout the body, potentially resulting in acute atherothrombotic events such as coronary artery disease (CAD), cerebrovascular disease (CVD), peripheral arterial disease (PAD) or a combination of all (polyvascular or diffuse vascular disease). These cardiovascular diseases cause 19 million deaths per year in the world. They are expected to be the main cause of death globally within the next 10 years owing to their rapidly increasing prevalence in developing countries, due to population aging and other factors, including the increase in unhealthy dietary patterns, physical inactivity, obesity and diabetes mellitus. ${ }^{1}$ Thus, the clinical burdent of atherosclerosis is likely to present enormous challenges in the future.

The current opinion is that atherosclerosis is an immune/inflammatory response of the intima to endothelial injury, mainly initiated by the transport of oxidised low-density lipoprotein (Ox-LDL) across 
the endothelium.2, 3 Several lines of evidence have shown that platelet interactions with modified lipoproteins seem to be quite important in triggering their transfer to the vessel wall. ${ }^{4}$ Platelets are by themselves inflammatory cells ${ }^{5}$ which can greatly influence monocyte and lymphocyte recruitment through interactions with the dysfunctional endothelium in a well-controlled process involving selectins and integrins. ${ }^{6,7,8}$ P-selectin-dependent formation of platelet-leucocyte aggregates (PLAs) further induces the release of a wealth of adhesive and pro-inflammatory substances. ${ }^{9}, 10$ The process continues in a vicious circle-like fashion and blood cells involved in adaptive immunity may play important roles in the self-perpetuating inflammatory process. ${ }^{11,12}$ Monocytes further differentiate into activated macrophages expressing scavenger receptors which bind different forms of OxLDL, leading to lipid-laden foam cells. ${ }^{13}$, 14 Platelets also act on the stability and vulnerability of lipid-rich plaques, through $\alpha$ llb $\beta 3$-mediated platelet-endothelium firm adhesion, CD40L expression and cytokine secretion ${ }^{15}$ which coordinate extracellular matrix proteins lysis by matrix metallo-proteases (MMPs), well-known to degrade and fragilize the fibromuscular cap. ${ }^{16,17}$

Thus, platelets foster an inflammatory environment that influences atherosclerotic plaque development and vulnerability, in addition to their role in acute thrombus formation. ${ }^{7}$

Traditionally, the degree of luminal stenosis has been used as a marker of the stage of atherosclerosis and as an indication for surgical intervention. Coronary angiography is the gold standard technique for lumenography, but unfortunately provides no information about the functional and molecular events leading to plaque rupture. ${ }^{18}$ Hence, imaging modalities with more pronostic value are highly desirable.

MRI approaches have successfully characterised carotid arteries, thanks to its high spatial resolution. ${ }^{19}$ However, up to now, the tortuosity and size of the coronary arteries added to the respiratory and cardiac motion hinder the in vivo imaging of coronary plaque. To overcome these problems and provide information on the molecular and cellular events leading to plaque rupture, we must rely on molecular imaging modalities, capable of reporting on the molecular content of the arterial wall.

In recent years, considerable efforts have been spent in the development of targeted magnetic contrast agents for biomedical imaging in MRI. ${ }^{20}$ These must be designed to have no toxicity and selective binding to desired epitopes such as cell surface receptors. ${ }^{21}$ With affinities classically in the nanomolar range, antibodies offer binding properties advantages over bio-mimetics and peptides. In order to ensure safety for medical purposes, human antibodies are preferred over murine antibodies (see limitation sections). Moreover, the choice of the targeted biomarker is of fundamental importance because it has to fulfil two criteria: (1) it must sign a pathological state and (2) it should be highly represented.

In light of the above arguments, we believe molecular targeting of platelets is relevant due to their important involvement into every stage of atheroma pathogenesis.

The remaining question concerns their localization and representativity: due to the variety of mecanisms allowing their internalisation - in addition to haemorrhage and thrombi - platelets are certainly retained within the plaque, providing novel means of discriminating atheroma plaques at high risk of rupture.

We thus developed a recombinant human antibody, rlgG4 TEG4, targeting human activated platelets, to be used as a targeting moiety. TEG4 human antibody was obtained through phage-display technology by biopanning on activated platelets. ${ }^{22}$ We now produced TEG4 in IgG4 format thanks to the baculovirusinsect cell system, in quantity sufficient to perform biofunctionalisation of nanoparticles. We then designed an original superparamagnetic iron oxide nanoparticle (VUSPIO for Versatile Ultra Small SuperParamagnetic Iron Oxide) ${ }^{23}$ (patent FR 2855315 (also published as EP 1627395 and WO 2004107368)) chosen as the contrast agent moiety to covalently couple rlgG4 TEG4 human antibody in order to ensure safety if inoculated in humans. 


\section{Methods}

\section{Production of TEG4 antibody as a recombinant $\operatorname{lgG}_{4}$ in baculovirus system}

The general principle is to replace a non-essential gene with a DNA sequence encoding a foreign protein of interest. This replacement is promoted by homologous recombination between DNA purified from a replication-defective baculovirus ${ }^{24,25}$ and a plasmid called "transfer vector" (pVT). Specific baculovirus cassettes have been designed ${ }^{26}$ to express the heavy and light chains of an antibody. These cassettes consist of (i) a strong very late viral promoter (P10 or polyedrin (PH)), (ii) a sequence encoding an immunoglobulin signal peptide, (iii) two unique restriction sites (AfIII-Nhel for heavy chain expression cassette and BssHII-Avrll for light chain expression cassette) to allow the insertion of the VH or VL sequences of the TEG4 anti- $\alpha$ llb $\beta 3$ antibody ${ }^{22,27}$, in frame with the upstream signal peptide sequence, and (iv) a downstream sequence that encodes the human heavy $(\gamma 4)$ or light chain $(\lambda)$ constant region. These cassettes are flanked by viral sequences that direct the integration of the foreign genes into a specific $\mathrm{P} 10$ or $\mathrm{PH}$ locus.

Recombinant IgG4 TEG4 was produced from Sf9 cells infected with the recombinant baculovirus coexpressing the TEG4 heavy and light chains. Recombinant IgG4 TEG4 was further purified on Protein A column (GE HealthCare Life Science,Velizy-Villacoublay, France). Details of cloning into transfer vectors, generation of recombinant viruses and purification of recombinant antibody are provided in online Supplementary Materials.

\section{Synthesis of TEG4-VUSPIO and control-VUSPIO conjugates}

The Versatile UltraSmall SuperParamagnetic Iron Oxide (VUSPIO) platform is based on $7.5 \mathrm{~nm}$-sized magnetic cores (maghemite $\mathrm{y}-\mathrm{Fe}_{2} \mathrm{O}_{3}$ ) functionalised by an aminated polysiloxane film grafted on their surface and embedded in a dextran corona. VUSPIO particles differ from USPIO contrast agents by its chemical stability thanks to strong covalent bonds established between magnetic cores and dextran macromolecules. Moreover, their surface is functionalised with long heterobifunctional poly(ethylene oxide) chains serving as cross linkers for derivatisation by fluorochromes and targeting agents. ${ }^{28,29}$

The rIgG4 TEG4 antibody conjugation to VUSPIO contrast agent is achieved by using SM(PEG) 24 (Thermo Scientific, Courtaboeuf, France) as coupling agent by converting the remaining primary amine terminal groups into maleimide functions. In parallel, a thiolation of TEG4 is performed with 2-Iminothiolane-HCL (Traut's Reagent), in order to introduce sulfhydryl groups. Detail of TEG4-VUSPIO is provided in online Supplementary Materials. Then the maleimide groups of VUSPIO react with the sulfhydryl groups of the antibody to form stable thioether bonds. A magnetic separation column (MACS, Miltenyi Biotec) was used to separate the unbound rlgG4 TEG4 from the magnetic conjugates.

The same experiments were performed with polyclonal IgG from human serum (Jackson Immunoresearch Laboratories, West Grove, PA, USA) and with human IgG4 isotypic control (kindly provided by M. Cérutti) to obtain IgG cont-VUSPIO and human IgG4 cont-VUSPIO respectively which served as negative controls for unspecific binding.

\section{Flow cytometry and optical microscopy imaging}

Aliquots of $10^{8}$ PFA-fixed-activated-platelets $(100 \mu \mathrm{L})^{27}$ were mixed with $25 \mu \mathrm{g} / \mathrm{mL}$ of rlgG4 TEG4 human antibody, AP-2 murine monoclonal antibody (courtesy of Dr Alan Nurden ${ }^{30}$ ) and other commercial antibodies (see online Supplementary Materials) targeting the $\alpha$ llb $\beta 3$ integrin or with specified dilutions

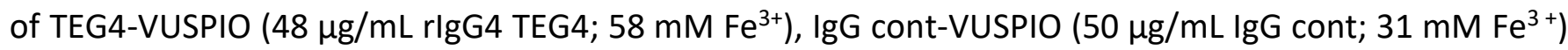


and antibody-free VUSPIO $\left(12 \mathrm{mM} \mathrm{Fe}^{3+}\right)$ overnight at $4{ }^{\circ} \mathrm{C}$ to obtain in fine $10 \mu \mathrm{g} / \mathrm{mL}$ of antibody and a minimum of $6.2 \mathrm{mM} \mathrm{Fe}^{3+}$. See online Supplementary Materials for the quantification of antibody conjugated to VUSPIO. After two washes in PBS, mixtures were re-suspended in appropriate volumes to perform flow cytometry ( $10^{6}$ platelets) and confocal microscopy studies ( $10^{8}$ platelets).

In flow cytometry experiments, aliquots of the cell samples were further incubated 30 minutes with secondary Alexa Fluor 488 goat anti-human H + L (Jackson Immuno Research Laboratories) (1/20), goat anti-mouse $H+L$ (Life Technologies, Saint-Aubin, France) (1/20) and fluorescein isothiocyanate (FITC) mouse anti-dextran antibodies (Stem-Cell Technologies, Grenoble, France) (1/5) for detection of respectively, the functionalising primary antibody (rlgG4 TEG4), murine AP-2 antibody and the dextran coating of antibody-conjugated VUSPIO nanoparticles.

For confocal experiments, aliquots of human platelets were re-suspended in $15 \mu \mathrm{L}$ anti-fading solution (Mowiol ${ }^{\circledR} 4-88$, Polysciences, Eppelheim, Germany). The digital microscope was a NIKON ECLIPSE 80i. The fluorescence emission was collected between 465 and $555 \mathrm{~nm}$.

\section{Immunohistochemical (IHC) analysis on murine and human atherosclerotic sections}

All animal studies were approved under the No. 50120192-A by the Animal Care and Use Committee of Bordeaux, France. Apo $\mathrm{E}^{-/-}$mice were fed a high-cholesterol diet for 21 weeks. Human coronary arteries were harvested from patients with end-stage heart failure having undergone heart transplantation. All of the clinical interventions took place at Haut-Lévèque Hospital (Pessac, France). Human tissue specimens were collected after informed consent. They were immediately processed and embedded in paraffin.

Paraffin-embedded sections of arterial tissue from mouse or human were used in IHC experiments with unconjugated antibodies (rlgG4 TEG4, AP-2, anti-CD41 ( $\alpha$ llb) (Abcam)), PAC-1 antibody ${ }^{31}$ (a murine antibody that binds to activated platelets, BD Biosciences), anti-CD68 (an antibody targeting macrophages, Dako, Les Ulis, France) or VUSPIO conjugated antibodies (TEG4-VUSPIO, IgG cont-VUSPIO) tested at $10 \mu \mathrm{g} / \mathrm{mL}$. See Supplementary Materials for details of the IHC experiment.

\section{Transmission electron microscopy}

TEG4-VUSPIO bound to activated platelets was visually analysed by using transmission electron microscopy. An electron microscopy study was conducted at BIC (Bordeaux Imaging Center, University Victor Segalen Bordeaux). Aliquots of $10^{8}$ human platelets activated with thrombin were fixed with $0.1 \%$ (v/v) glutaraldehyde/1.5\% (v/v) paraformaldehyde and mixed with TEG4-VUSPIO and IgG cont-VUSPIO in $0.1 \mathrm{M}$ phosphate buffer. See online Supplementary Materials for details of the experiment.

\section{Magnetic resonance imaging}

In vitro MR imaging for relaxivity measurement and for quantification of TEG4-VUSPIO nanoparticles per platelet is described in online Supplementary Materials.

Ex vivo MR imaging was performed using a 9.4 Tesla MRI system (Bruker) (inner coil diameter, $10 \mathrm{~mm}$ ) on healthy or atherosclerotic aorta, respectively from C57BL/6 wild-type or ApoE ${ }^{-/-}$mice $(n=3)$ terminally anaesthesised by inhalation of isoflurane. The chest was opened by thoracotomy, the heart exposed and the right atrium cut. A 30-gauge needle was inserted in the left ventricle. PBS-heparin $(50 \mathrm{UI} / \mathrm{mL} ; 2.5 \mathrm{~mL}$ (Sanofi Aventis, Vitry-sur-Seine, France)) was inoculated followed by $10 \mathrm{~mL}$ PBS. Perfusion was continued with $2 \mathrm{~mL}$ of PBS containing a formulation of either TEG4-VUSPIO $\left(20 \mu \mathrm{L} ; 58 \mathrm{mM} \mathrm{Fe}^{3+}\right)$ or IgG cont-VUSPIO $\left(38 \mu \mathrm{L} ; 31 \mathrm{mM} \mathrm{Fe}^{3+}\right.$ ) or PBS. After $20 \mathrm{~min}$, mice were again perfused with $10 \mathrm{~mL}$ PBS followed by $5 \mathrm{~mL}$ of 
$4 \% \mathrm{v} / \mathrm{v}$ paraformaldehyde (PFA). The aorta was then removed and embedded in a glass MR tube containing $0.8 \% \mathrm{p} / \mathrm{v}$ high-grade, low melting-point agarose. Imaging parameters (FAST low-angle shot three-dimensional sequence) included the following: $T E=8 \mathrm{~ms} ; \mathrm{TR}=27 \mathrm{~ms}$; field of view $10 \times 10 \times 10 \mathrm{~mm}^{3}$; image resolution $0.039 \times 0.067 \times 0.067 \mathrm{~mm} /$ pixel; acquisition time: overnight; 48 scans.

\section{Results}

\section{Production of TEG4 antibody as a recombinant $\operatorname{lgG}_{4}$ in baculovirus system}

After purification on Protein A, silver-stained SDS-PAGE under reducing and non-reducing conditions revealed proteins corresponding to the expected size of a correctly processed IgG4 and no major additional band (data not shown). Five milligrams of purified recombinant TEG4 (rlgG4 TEG4) was produced and the specificity of the recombinant molecules was controlled by ELISA on the $\alpha$ llb $\beta 3$ integrin (data not shown).

\section{Comparison of rlgG4 TEG4 and AP-2 binding against human platelets and atheroma}

The murine monoclonal antibody, designated AP-2, reacts specifically with the complex formed by the human platelet membrane glycoproteins $\alpha \mathrm{llb}$ and $\beta 3$. The human antibody TEG4 was previously obtained through phage-display biopanning against activated platelets, and characterised as an anti- $\alpha$ llb $\beta 3$ antibody. ${ }^{22}$

AP-2 and rlgG4 TEG4 were first tested in flow cytometry and optical microscopy experiments against human thrombin-activated platelets (Figure 1, A). Due to the high number (50,000 copies) of $\alpha$ llb $\beta 3$ integrins on the surface of activated platelets, this specificity results in a significant shift of fluorescence when aliquots of $10^{6}$ PFA-fixed-activated platelets were incubated with AP-2 antibody (Figure 1, $A, b$; Table 1 (geometric mean: 13,270; median: 12,180)). The same shift of fluorescence was observed with the rlgG4 TEG4 human antibody (Figure 1, A, e; Table 1 (geometric mean: 17,390; median: 25,340)). Activated platelets incubated with either AP-2 or rlgG4 TEG4 showed a fine labelling in optical microscopy (Figure 1, $A, c, f$ ). 
A

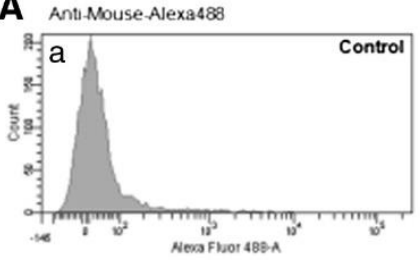

Ant-Human-Alexa488

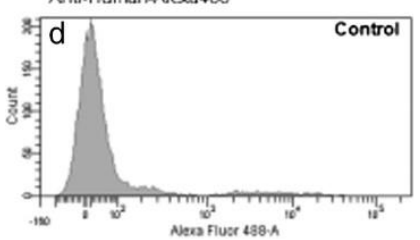

B Anti-Human-Aleca488

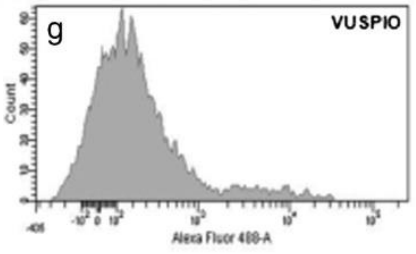

Ant-Dextran-FITC

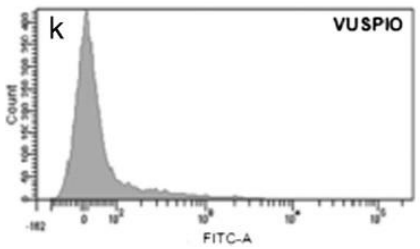

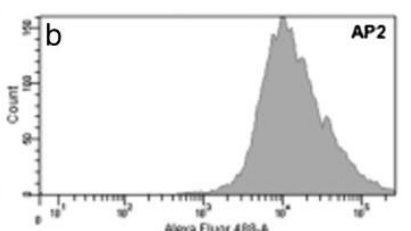
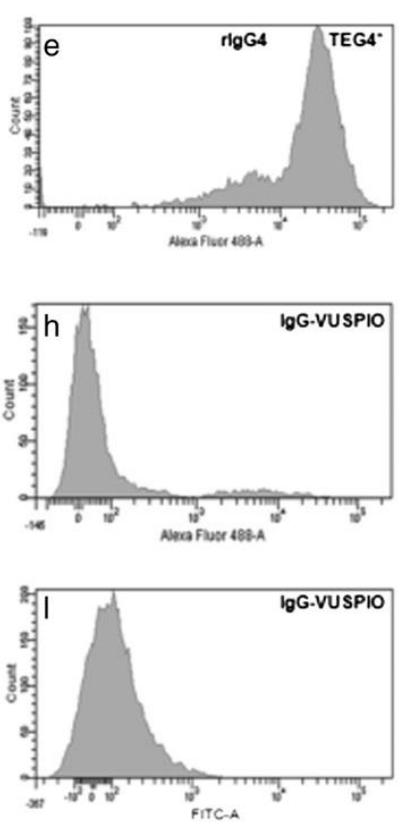
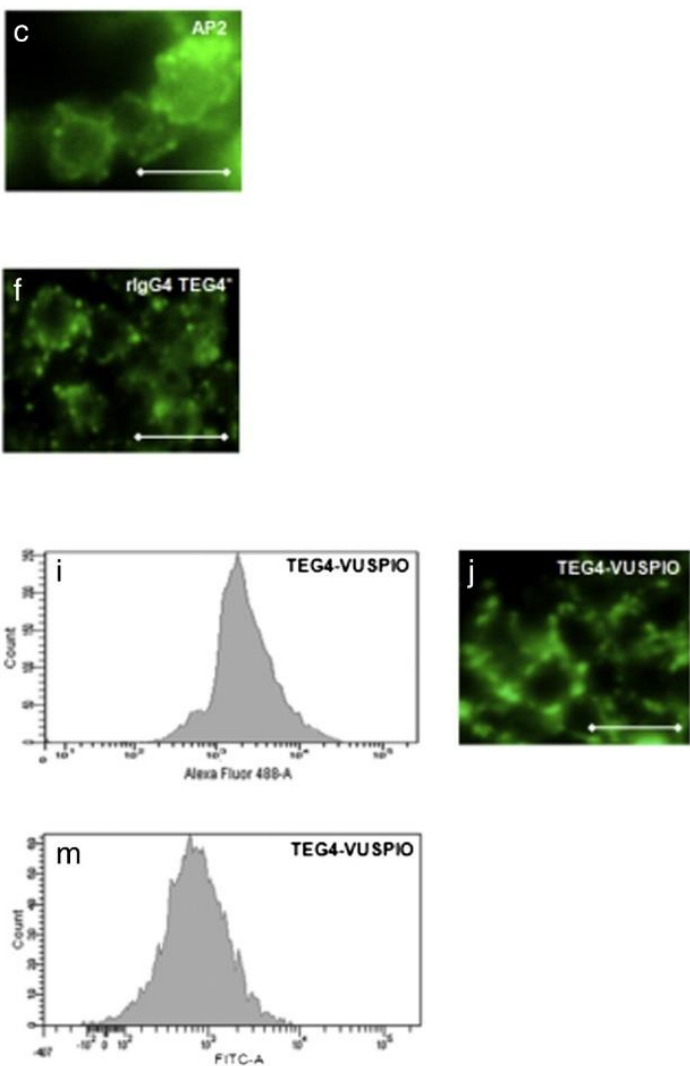

Figure 1. Flow cytometry and optical fluorescence microscopy assays performed on PFA-activated platelets. Incubations with AP-2 murine monoclonal antibody or rIgG4 TEG4 human monoclonal antibody (A), and TEG4-VUSPIO contrast agent or IgG cont-VUSPIO $(\boldsymbol{B})$ were followed by a second incubation with species-specific secondary antibodies labelled with Alexa Fluor 488 or anti-dextran antibodies labelled with FITC. The labelling of platelets in flow cytometry $(\boldsymbol{B}, \boldsymbol{i}, \boldsymbol{m})$ and optical microscopy $(\boldsymbol{B}, \boldsymbol{j})$ with the TEG4-VUSPIO conjugate is similar to the labelling with rIgG4 TEG4 human antibody $(\boldsymbol{A}, \boldsymbol{e}, \boldsymbol{f})$. Bar: $5 \mu \mathrm{m}$.

Table 1

Results of cytometry.

\begin{tabular}{|c|c|c|c|c|c|c|}
\hline \multirow[t]{3}{*}{ Antibody } & \multicolumn{6}{|c|}{ Flow cytometry results } \\
\hline & \multicolumn{2}{|c|}{ Anti mouse Antibody } & \multicolumn{2}{|c|}{ Anti human Antibody } & \multicolumn{2}{|c|}{ Anti dextran Antibody } \\
\hline & Geometric mean & Median & Geometric mean & Median & Geometric mean & Median \\
\hline Unconjugated $\mathrm{AP}-2^{\#}$ & 13,270 & 12,181 & & & & \\
\hline Unconjugated TEG4 ${ }^{\#}$ & & & 17,386 & 25,338 & & \\
\hline Unconjugated TEG4 * & & & 4038 & 2258 & & \\
\hline IgG cont-VUSPIO* & & & 273 & 229 & 142 & 142 \\
\hline TEG4-VUSPIO * & & & 2086 & 1966 & 744 & 740 \\
\hline Ab-free VUSPIO & & & 154 & 73 & 209 & 166 \\
\hline
\end{tabular}

The reactivity of TEG4 antibody is similar to AP-2, a mouse antibody targeting activated platelets.

TEG4-VUSPIO revealed anti-platelet target recognition as compared to antibody-free VUSPIO particles and IgG cont-VUSPIO particles.

* $10 \mu \mathrm{g} / \mathrm{mL}$

\# $25 \mu \mathrm{g} / \mathrm{mL}$

\section{Number of human antibodies per nanoparticle}

The absorbance of the VUSPIO samples was measured at $480 \mathrm{~nm}$ using a spectrophotometer (U-2800A spectrophotometer, Hitachi). The iron content of samples of conjugated and unconjugated VUSPIO was

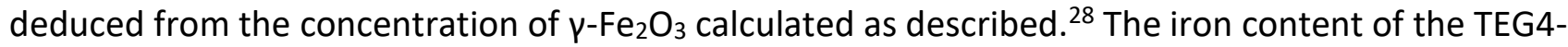
VUSPIO conjugate was $3.25 \mathrm{~g} / \mathrm{L} \mathrm{Fe}^{3+}\left(\mathrm{Fe}^{3+}=58 \mathrm{mM}\right)$ and the antibody concentration calculated from ELISA curves was $48 \mu \mathrm{g} / \mathrm{mL}$, leading to a ratio of one antibody per VUSPIO. 


\section{Analysis of TEG4-VUSPIO reactivity against platelets by fluorescence}

The human recombinant monoclonal antibody rIgG4 TEG4 and polyclonal IgG conjugated to VUSPIO nanoparticles (TEG4-VUSPIO and IgG cont-VUSPIO) were incubated with aliquots of PFA-fixed-activated platelets (Figure 1, B). Unconjugated rlgG4 TEG4 antibody at $10 \mu \mathrm{g} / \mathrm{mL}$ and antibody free-VUSPIO at $12 \mathrm{mM} \mathrm{Fe}^{3+}$ (Figure $1, B, g, k$ ) were used as positive and negative controls respectively. For flow cytometry detection of antibody-VUSPIO, aliquots of the cell samples were further treated with Alexa Fluor 488 goat anti-human $\mathrm{H}+\mathrm{L}$ or FITC anti-dextran antibodies. The first method indirectly detects targeted contrast agents accumulated all around platelets by staining the targeting ligand (e.g. the functionalising primary antibody) with a secondary antibody (anti-human $\mathrm{H}+\mathrm{L}$ ) recognising the primary human antibody. The second method, using an anti-dextran antibody, is useful to detect the nanoparticle by itself.

Flow cytometry using both secondary antibody systems revealed a distinct fluorescence shift of platelets incubated with TEG4-VUSPIO compared to antibody-free VUSPIO and IgG cont-VUSPIO controls (Figure 1, $B$ ). Using anti-human $\mathrm{H}+\mathrm{L}$ and anti-dextran antibodies, a 7.6 and 5.2 enhancement in targeting was observed respectively for the geometric mean between the contrast agent functionalised with rlgG4 TEG4 and the same agent functionalised with an irrelevant antibody (Figure 1, B, i, $m, h$, l; Table 1). Moreover, quite the same platelet recognition was shown with free rlgG4 TEG4 at $10 \mu \mathrm{g} / \mathrm{mL}$ and rlgG4 TEG4 grafted on VUSPIO nanoparticles (4040 versus 2090 for the geometric mean and 2260 versus 1970 for the median (Table 1)).

Geometric mean and median values in flow cytometry corroborate the high fluorescence labelling of free rlgG4 TEG4 and TEG4-VUSPIO on activated platelets in optical microscopy.

\section{Analysis of TEG4-VUSPIO reactivity against platelets by TEM and in vitro MRI}

Another way to obtain a direct representation of the active targeting of the nanoparticle by itself is to perform TEM analysis on activated platelets. Binding experiments were performed with thrombinactivated platelets using either TEG4-VUSPIO or IgG cont-VUSPIO. TEG4-VUSPIO targeted contrast agent was particularly visible at the platelet periphery, along the plasma membrane (Figure 2, $A$, blacks arrowheads). Of particular interest was the binding of TEG4-VUSPIO to activated platelets characterised by irregular forms with many irradiating pseudopodes projecting from their surface. In contrast, no labelling was evidenced at the plasma membrane when IgG cont-VUSPIO was used (Figure 2, $A,(g, h)$ ). Figure $2, A, i$ is a TEM analysis of TEG4-VUSPIO nanoparticles.

Figure 2, $B$ describes in vitro MRI platelet experiments assessing the binding of targeted and untargeted VUSPIO to activated platelets. In comparison to the signal obtained with platelets only, T2-weighted MR imaging of platelet phantoms incubated with TEG4-VUSPIO (Figure 2, $B, a$ ) revealed a significant signal loss, in the same order of VUSPIO nanoparticles at $250 \mu \mathrm{M} \mathrm{Fe}{ }^{3+}$ (Figure $2, B, b$ ). A minor signal loss was observed for platelets incubated with antibody-free VUSPIO particles and IgG4 cont-VUSPIO (Figure 2, $B,(e, c)$ ) when compared with platelet alone without any VUSPIO (Figure 2, $B$, g). Fewer VUSPIO nanoparticles remain trapped after two washes using IgG4 cont-VUSPIO (Figure 2, $B, C$ ) compared with antibody-free VUSPIO (Figure $2, B, e$ ). These results suggest that - $\mathrm{NH} 2$ functional groups in antibody-free VUSPIOs are involved in residual nonspecific uptake, compared with nanoparticles whose amine groups were shielded by conjugated control antibodies. R2 relaxation rates of cell pellets treated with TEG4VUSPIO, IgG4 cont-VUSPIO, unconjugated VUSPIO and with PBS only were $47.7 \pm 3.5 \mathrm{~s}^{-1}, 7.8 \pm 2.1 \mathrm{~s}^{-1}$, $10.9 \pm 1.9 \mathrm{~s}^{-1}$ and $4.4 \pm 1.2 \mathrm{~s}^{-1}$ respectively. 


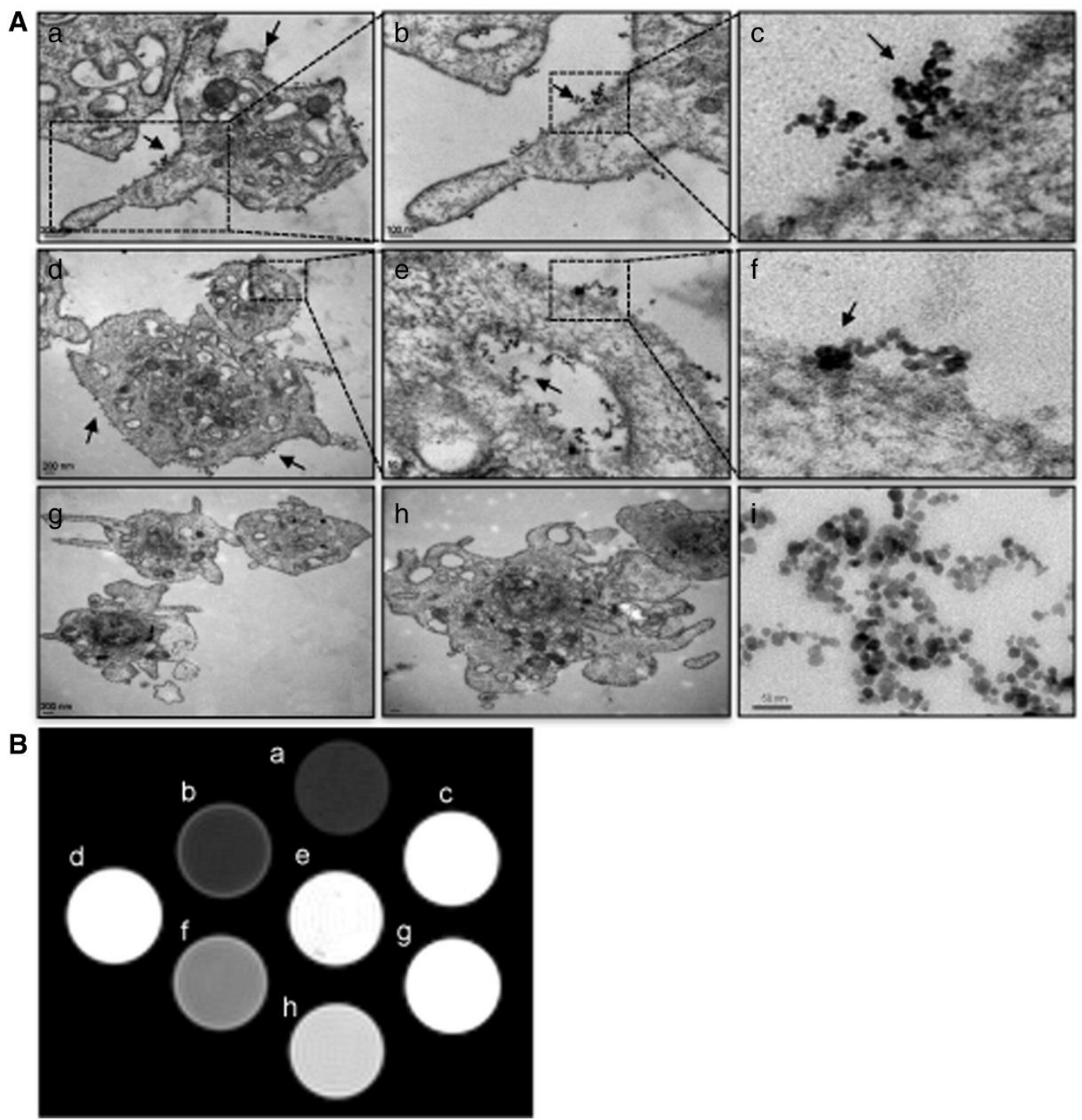

Figure 2. In vitro validation of platelet targeting by transmission electron microscopy (TEM) and T2-weighted MRI on phantoms.

(A) TEM images of TEG4-VUSPIO nanoparticles targeting activated platelets. TEM images clearly show the presence of contrast agents as dots distributed all around the platelets (arrowheads), especially in the pseudopodia developed in activated platelets $(\boldsymbol{a}, \boldsymbol{b}, \boldsymbol{c}) . \boldsymbol{b}, \boldsymbol{c}$ and $\boldsymbol{e}, \boldsymbol{f}$ are zoomed frames of a and $d$ respectively, indicated by dashed lines. The same platelets incubated with IgG cont-VUSPIO showed no VUSPIO labelling $(\boldsymbol{g}, \boldsymbol{h})$. (i) illustrated the TEG4-VUSPIO preparation at $48 \mathrm{mM} \mathrm{Fe} \mathrm{e}^{3+}$.

(B) T2 MR images of activated platelets targeted by TEG4-VUSPIO (a) shows the MRI signal obtained with TEG4-VUSPIO compared with the MRI signal of different concentrations of VUSPIO $\left(0 \mu M F e^{3+}(\boldsymbol{d}), 62.5 \mu M F e^{3+}(\boldsymbol{h}), 125 \mu M F e^{3+}(\boldsymbol{f}), 250 \mu M\right.$ $\left.\mathrm{Fe}^{3+}(\boldsymbol{b})\right)$ in agarose gel, untargeted VUSPIOs (e), IgG4 cont-VUSPIO (c), platelets only (g). The TEG4-VUSPIO signal loss was in the same range of free VUSPIOs at $250 \mu \mathrm{MFe} e^{3+}(\boldsymbol{b})$, indicating the efficiency of targeting.

These values and the curve correlating the 1/T2 values measured at 4.7 Tesla with $\mathrm{Fe}^{3+}$ concentrations were used to estimate the number of TEG4-VUSPIO nanoparticles bound per platelet. We found approximately 170 TEG4-VUSPIO per platelet which corroborates the number of counted targeted nanoparticles on TEM images.

\section{Analysis of TEG4-VUSPIO reactivity against human and murine atheroma by immunohistochemistry}

The presence of platelets within the atheroma plaque of $\mathrm{ApoE}^{-/-}$and human coronary specimens was tested using murine (AP-2) and human (rlgG4 TEG4) antibodies targeting the $\alpha$ llb $\beta 3$ integrin and 
confirmed by commercial antibodies (anti-CD41 and PAC-1, respectively). Arterial sections from ApoE ${ }^{-/-}$ mice showed a strong labelling of the intima in atheroma with both anti-platelet antibodies (Figure $3, D$, $F$ ). The same staining was obtained with a commercial antibody (Figure $3, B$ ) and controls were performed with appropriate secondary antibodies (Figure $3, A, C, E$ ). The same strong labelling was observed when sections of human coronary specimens were incubated either with AP-2 or rlgG4 TEG4 antibodies (Figure $4, B, C$ and $E, F$, respectively). This result was confirmed by the commercial antibody PAC-1 (Figure $4, H, I$ ). Enlarged views (Figure $4, C, F, I$ ) showed the targeting of small neovessels located within the intima, in the desorganized media. The staining of macrophages by anti-CD68 antibody (Figure $4, K, L$ ) matches some of the regions where platelets are found (Figure $4, E, H$ ), suggesting the localisation of platelets in areas of foam cells and platelet-leucocytes-aggregates (PLA) accumulation. No labelling was observed with controls performed with appropriate secondary antibodies (Figure $4, A, D, G, J$ ).
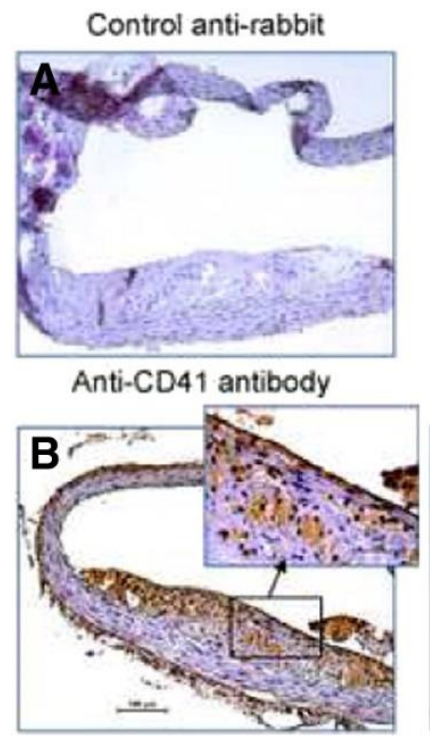

Control anti-mouse

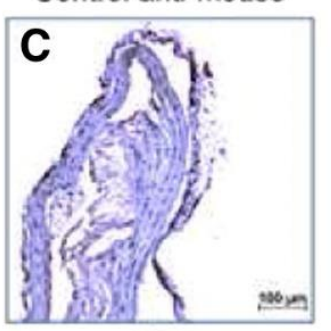

AP-2

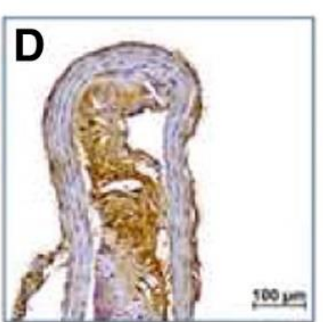

Control anti-human $\mathrm{H}+\mathrm{L}$

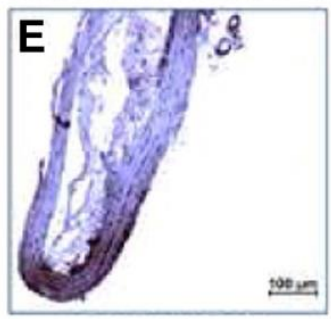

TEG4-VUSPIO IgG cont-VUSPIO
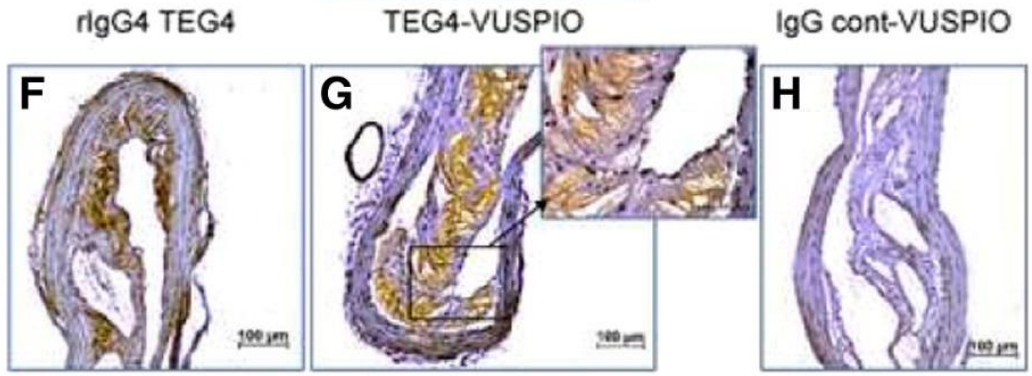

Figure 3. Immunohistochemical detection of integrin $\alpha I$ IIb3 on aorta sections from ApoE ${ }^{-/-}$mice. The presence of platelets was shown using two different mouse antibodies: a commercial anti-CD41 ( $\alpha I I b)$ antibody (B) and an antibody (AP-2) specific to the complex $\alpha I I b \beta 3(\boldsymbol{D})$. Controls were performed with secondary HRP-labelled anti-rabbit and anti-mouse antibodies $(\boldsymbol{A}, \boldsymbol{C})$. The human antibody rIgG4 TEG4 $(\boldsymbol{F})$ recognises platelets at the same level as both murine anti- $\alpha I I b \beta 3$ antibodies. The conjugate TEG4-VUSPIO shows a high labelling of platelets within the intima $(\boldsymbol{G})$ contrary to IgG cont-VUSPIO (H). Controls were performed with a secondary HRP-labelled anti-human $H+L$ antibody $(\boldsymbol{E})$. Bar: $100 \mu \mathrm{m}$ and $50 \mu \mathrm{m}$ for enlarged views.
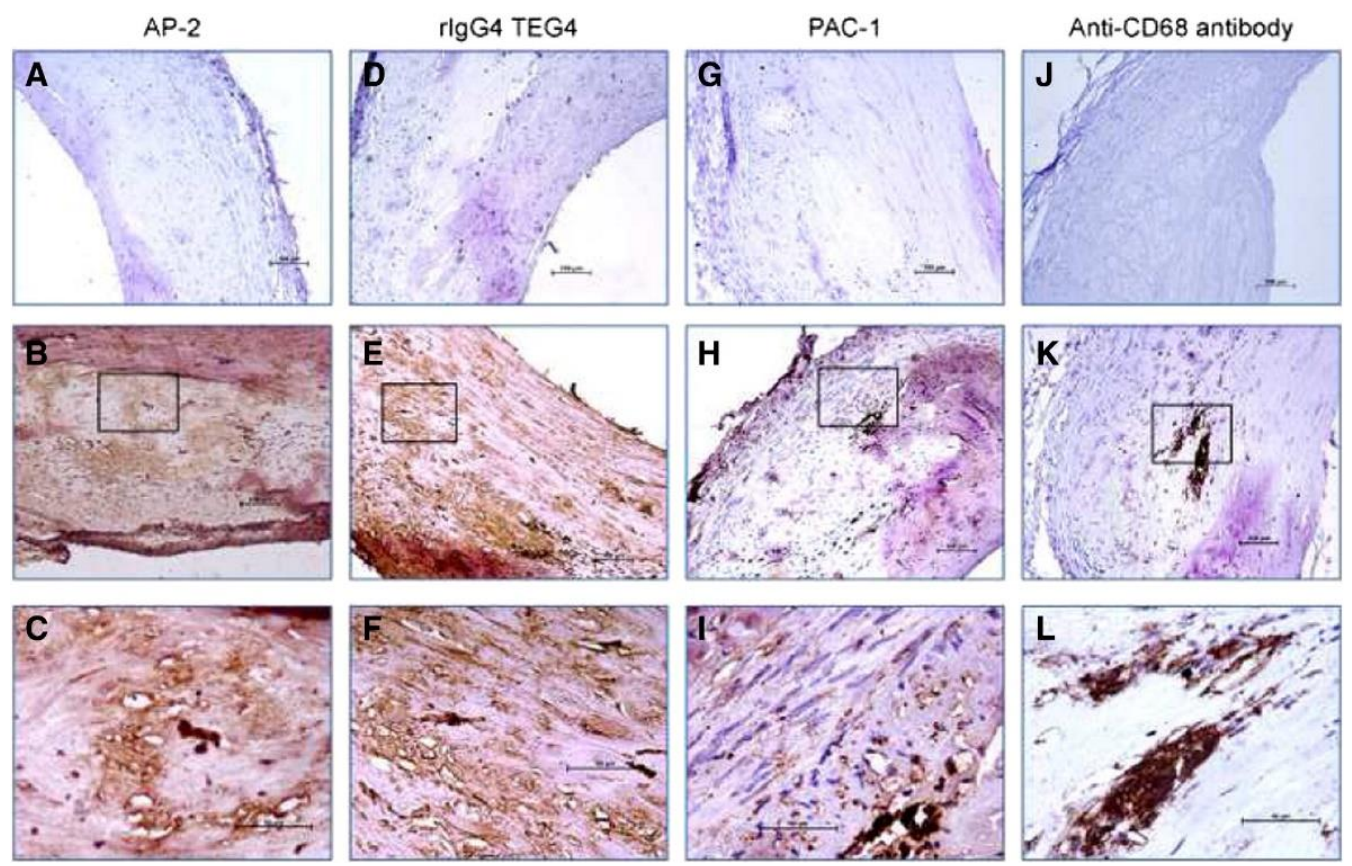
Figure 4. Immunohistochemical detection of integrin $\alpha I$ IIb33 on coronary human sections. AP-2 and rIgG4 TEG4 panels: the presence of platelets was shown using the mouse anti- $\alpha I I b \beta 3$ antibody AP-2 $(\boldsymbol{B}, \boldsymbol{C})$ and the human antibody rIgG4 TEG4 $(\boldsymbol{E}, \boldsymbol{F})$. PAC-1 panel: the presence of platelets was confirmed with a commercially available mouse antibody specific to human activated $\alpha I I b \beta 3(\boldsymbol{H}, \mathbf{I})$. Anti-CD68 panel: foam cells were detected with a commercially available mouse antibody specific to human CD68. $(\boldsymbol{C}, \boldsymbol{F}, \boldsymbol{I}, \boldsymbol{L})$ are enlerged views of $(\boldsymbol{B}, \boldsymbol{E}, \boldsymbol{H}, \boldsymbol{K})$. Controls were performed with secondary HRP-labelled anti-mouse IgG antibody $(\boldsymbol{A}, \boldsymbol{J})$, HRP-labelled anti-human $H+$ L antibody $(\boldsymbol{D})$ and HRP-labelled anti-mouse IgM antibody $(\boldsymbol{G})$. Bars: $100 \mu \mathrm{m}$ and $50 \mu \mathrm{m}$ for enlarged views.

The targeted contrast agent TEG4-VUSPIO was tested on sections of ApoE ${ }^{-/-}$(Figure 3, G) and wild-type C57BL/6J mice (Supplementary data, Figure S3, C), showing a high labelling of platelets within the intima of $\mathrm{ApoE}^{-/-}$mouse (Figure 3, G) contrary to IgG cont-VUSPIO (Figure 3, H). VUSPIO conjugates tested on wild-type C57BL/6J mice (Supplementary data, Figure S3, B, C) and appropriate secondary antibody (Supplementary data, Figure $\mathrm{S} 3, A$ ) showed no labelling.

These in vitro results confirm the maintenance of TEG4 specificity after coupling to VUSPIO nanoparticles.

\section{Ex vivo characterisation of the targeted-contrast agent nanoparticle}

Atherosclerotic plaques in $\mathrm{ApoE}^{-/-}$mice thoracic aorta are clearly visible at 9.4 Tesla (Figure $5, B$ ) when compared with healthy aorta of C57BL/6 wild type mice (Figure $5, A$ ). The aorta from atherosclerotic $\mathrm{ApoE}^{-/-}$mice exposed ex vivo to TEG4-VUSPIO preparation shows an intense hypo-signal (black arrows) (Figure $5, C$ ). In contrast, no hypo-signal was observed in the thoracic aorta of $\mathrm{ApoE}^{-/-}$mice that did not receive VUSPIO (Figure $5, B$ ) or did receive IgG cont-VUSPIO (Figure $5, D$ ). Thus, representative ex vivo MRI studies at 9.4 Tesla showed that TEG4-VUSPIO could induce a loss of MRI signal generated by VUSPIO accumulation in the atherosclerotic vessel wall of $\mathrm{ApoE}^{-/-}$mice, due to antibody targeting.

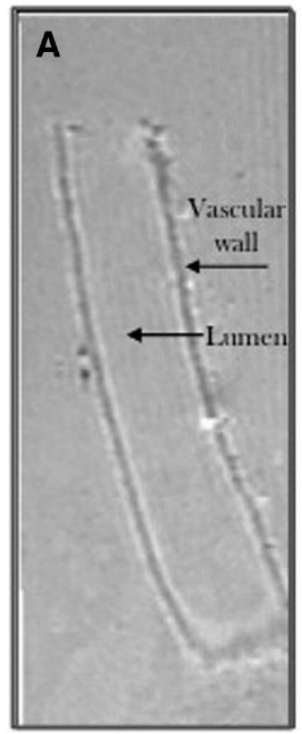

Healthy aorta

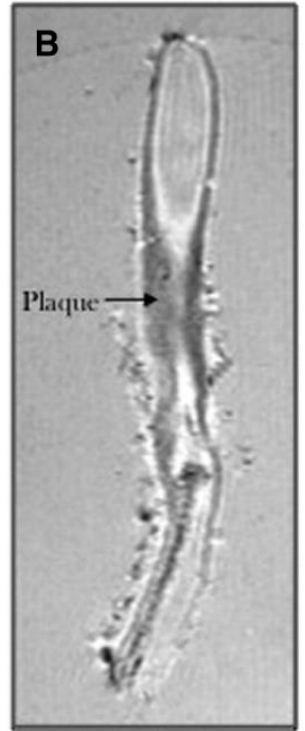

ApoE $^{-/}$aorta

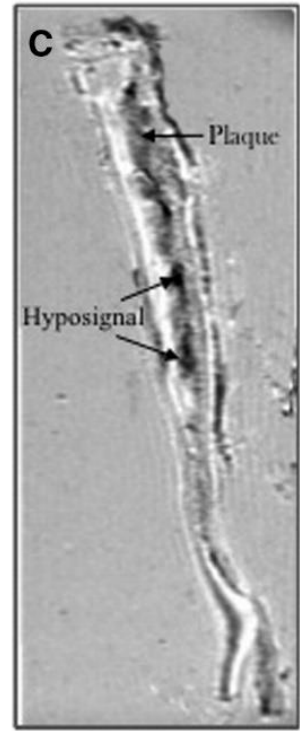

ApoE ${ }^{-*}$ aorta

TEG4-VUSPIO

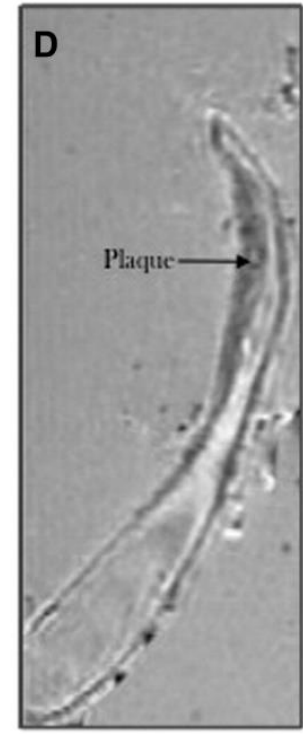

ApoE $\%$ aorta

IgG cont-VUSPIO

Figure 5. Ex vivo MRI at 9.4 Tesla. The healthy $(\boldsymbol{A})$ or atherosclerotic ApoE ${ }^{-/-}$aorta $(\boldsymbol{B}, \boldsymbol{C}, \boldsymbol{D})$ were perfused ex vivo with PBS $(\boldsymbol{A}, \boldsymbol{B}), T E G 4-V U S P I O(C), I g G$-cont VUSPIO (D). No atherosclerotic plaque was visible in healthy aorta $(\boldsymbol{A})$. Panel $C$ shows an intense hyposignal due to iron deposition within atherosclerotic plaque. In contrast, no loss of signal was observed when IgG cont-VUSPIO was administered $(\boldsymbol{D})$.

\section{Discussion}

This study demonstrates the interest of non invasive imaging of platelets recruited within atherosclerotic lesions by an $\alpha$ llb $\beta 3$-targeted VUSPIO molecular imaging probe. The presence and effects of platelets 
inside the atherosclerotic plaque are relatively underexplored and this probe could give insight into intraplaque haemorrhage (IPH), neovasculature and vascular wall inflammation which constitute key plaque features underlying atherosclerosis.

The rationale for molecular imaging is to propose an accurate diagnosis method. Prospective clinical trials have shown that measurement of stenosis underestimates carotid plaque burden ${ }^{18}$ and that the majority of patients with a history of recent transient ischemic attack (TIA) or stroke have mild-to moderate carotid stenosis. Debates still exist on how stenosis severity is related to the unstability of the culprit lesions. ${ }^{32}$ However, data from the PROSPECT (Providing Regional Observations to Study Predictors of Events in the Coronary Tree) study have concluded that a small luminal area is independently associated with the 3year risk of acute coronary events. ${ }^{33} \mathrm{It}$ is now admitted that looking beyond the lumen with functionalised contrast agents is needed to identify the high-risk plaques across a range of stenoses issuing from both carotid and coronary beds.

Compared to previous approaches using rodent antibodies, the use of a human antibody to functionalise nanoparticles is of particular interest for direct transfer into the clinic, considering the need of repeated injections to follow the progression of the disease. Using human antibodies may reduce immunogenicity by avoiding the development of anti-species antibodies usually described when murine antibodies were injected in humans. ${ }^{34}$ (see Limitations section).

Recombinant IgG4 TEG4 antibody is able to target activated platelets in the same level as the murine AP2 and anti-CD41 antibodies as demonstrated by fluorescence experiments. Our in vitro experiments conducted with the targeted contrast agent TEG4-VUSPIO confirmed maintenance of specificity against activated platelets using fluorescence and TEM. In vitro MRI results also showed that the activated platelets targeted with TEG4-VUSPIO have the highest signal reduction (R2 relaxation rate of $47.7 \pm 3.5 \mathrm{~s}^{-1}$ ) when compared with IgG4-cont VUSPIO, unconjugated VUSPIO and with PBS only (R2 relaxation rates of $7.8 \pm 2.1 \mathrm{~s}^{-1}, 10.9 \pm 1.9 \mathrm{~s}^{-1}$ and $4.4 \pm 1.2 \mathrm{~s}^{-1}$ respectively), highlighting the added value of targeting versus passive take up of nanoparticles. All these results demonstrate that TEG4-VUSPIO can selectively accumulate around activated platelets. Recombinant IgG4 TEG4 antibody and TEG4-VUSPIO contrast agent were also shown to highly label atherosclerotic sections of murine and human specimens as demonstrated by IHC studies.

The rationale for targeting platelets within atherosclerotic lesions is that they are highly represented not only in thrombi and intraplaque haemorrhage (IPH) but also in atheroma burden, around necrotic areas and neovessels (see Figure 3, Figure 4). A pioneer study performed by Massberg et $\mathrm{al}^{6}$ showed, by intravital videofluorescence microscopy, that platelets adhering at the carotid bifurcation (lesion-pronesite) in $\mathrm{ApoE}^{-/-}$mice, directly coincided with inflammatory gene expression and preceded atherosclerotic plaque invasion by leukocytes. Platelet-endothelial interactions linked to increased inflammatory activation and prothrombotic state in atherosclerosis are mediated, in part, by platelet glycoprotein (GP) Ib $\alpha$. Jonathan Lindner's group ${ }^{35}$ used recombinant GPIb as a targeting moiety on microbubble contrast agents to perform contrast-enhanced ultrasound molecular imaging of activated von Willebrand factor (VWF) and thus demonstrated widespread platelet-endothelial interaction in LDLR $\mathrm{R}^{-/-} / \mathrm{ApoBec}-1^{-/-}$mice.

Since then, many studies indicate that platelets not only contribute to endothelial dysfunction but also modulate various inflammatory responses by platelet-monocyte complex formation (PMA: plateletmonocyte aggregates) ${ }^{36,37}$ or platelet-CD4 ${ }^{+} \mathrm{T}$ cell cross-talk ${ }^{38}$, facilitating leucocyte transmigration and thus act on plaque vulnerability. Platelets themselves - like monocytes/macrophages - are able to bind, take up via scavenger receptors (CD36, LOX-1, SR-B1) and transport modified lipoproteins into the intima, thus contributing indirectly and directly to foam cell formation in atherogenesis. ${ }^{4}$ Inside the plaque they are in close contact with macrophages and phagocytosis of platelets by macrophages was already 
proposed as an alternative mechanism of foam cell formation 53 years ago by Chandler et al. ${ }^{39}$ Four decades later, De Meyer et al $^{40}$ confirmed in vitro that platelet phagocytosis by murine macrophages results in the formation of lipid-laden macrophages. The authors concluded that uptake of modified LDL by platelets and phagocytosis of LDL-laden platelets by macrophages may be critical steps for the development of lipid-rich plaques. Daub et $\mathrm{al}^{41}$ more recently showed that platelet oxLDL contributes significantly to vascular inflammation and is able to promote atherosclerosis. Platelet-induced lipid accumulation in monocytes thus provides a novel mechanism for how platelets negatively regulate plaque stability. ${ }^{8}$ Furthermore, platelets are contained in large amounts in early-calcified human atherosclerotic plaques as the results of plaque neovascularisation by leaky vessels, blood extravasation and haemorrhage. They have been involved in the release of osteocalcin in atherosclerotic lesions. ${ }^{42}$ Thus, results from the literature and the high labelling shown in Figure 3, Figure 4 of this study prove that platelets are not only present on plaque surfaces or in IPH. They may play, outside thrombi formation, an important role in inflammation, necrotic core formation, release of factors like osteocalcin and matrix metalloproteinases ${ }^{43}$ involved in plaque destabilisation.

So far, the proof of entry of platelets into atherosclerotic lesions has only been given in human atheroma and it was correlated with intraplaque microvascular leakage and IPH. ${ }^{44}$ Mice atheroma does not typically develop IPH. This means that the different antibodies (TEG4, AP-2, anti-CD41 antibody) used in IHC recognise platelets within $A p o E^{-/-}$mice atheroma which are not involved in intraplaque thrombi but are rather in interaction with other cells as reported in platelet-leucocyte aggregates (PLA). That is why our study is important from a fundamental point of view because it sheds light into the significant presence of platelets both within mouse and human atheroma as demonstrated in Figure 3, Figure 4 by IHC on sections of $\mathrm{ApoE}^{-/-}$aorta and human coronary arteries.

Moreover, MRI approaches have shown that complex plaque features, such as the necrotic core and intraplaque haemorrhage are prevalent in carotid arteries with minimal stenosis, including those with angiographically normal appearing arteries. ${ }^{45}$ Thus, the development of probes that package MRI contrast agents with ligands targeting platelets might show great promise for providing a direct measure of plaque activity and function at the cellular and molecular level. In the current study, the ex vivo results highlighted an accumulation of the targeted contrast agent in the atherosclerotic vessel wall of $\mathrm{ApoE}^{-/-}$mice.

Cheruvu and colleagues showed that plaque composition varies depending on the anatomical site with striking heterogeneity even within the same individual. ${ }^{46}$ Therefore, the finding of a focal distribution of suspected precursor lesions supports the efforts to develop reliable non-invasive imaging tools to identify the molecular and cellular composition of these structures that may occur at sites with and without flowlimiting stenoses.

This manuscript describes the development of a new targeted contrast agent for MRI, from the conception of the targeting moiety, a fully human antibody, to ex vivo MRI images.

\section{Limitations}

Today, most therapeutic mAbs in the clinic are humanised or fully human meaning that, theoretically, only a minimal immunogenic potential remains (as compared to murine mAbs). ${ }^{47}$ However, evolution of recombinant technologies to produce fully human antibodies has only partially solved this historic obstacle of antibodies. Immunogenicity induced by injected proteins is a serious issue because it is directly related to the patient's safety. A risk assessment should be conducted for every biotherapeutic under development to address the occurrence of immunogenicity, as well as the severity of the adverse effects caused. An induced antibody response against human antibodies, called human anti-human antibody (HAHA) response, must always be thoroughly tested in clinical studies. ${ }^{48}$ In regard of that, the present 
study has limitations inherent to potential immunogenicity against the injected targeted contrast agent. Even if we have been careful to develop fully human antibodies to serve as the ligand moiety, it is impossible to guarantee, before clinical assays in a cohort of individuals, that anti-idiotypic antibodies will not arise. Moreover, the development of immunogenicity during treatment is highly dependent, not only of the individual status, but also of the pathology treated (immune disorders, chronic illnesses are more at risk to induce auto-antibodies formation) and of the target protein and mechanism of action. ${ }^{49,50}$

\section{Appendix A. Supplementary data}

\section{References}

1. C. Psarros, R. Lee, M. Margaritis, C. Antoniades. Nanomedicine for the prevention, treatment and imaging of atherosclerosis. Nanomedicine, 8 (Suppl. 1) (2012), pp. S59-S68.

2. D.I. Siegel-Axel, M. Gawaz. Platelets and endothelial cells. Semin Thromb Hemost, 33 (2007), pp. 128-135.

3. N.R. Madamanchi, A. Vendrov, M.S. Runge. Oxidative stress and vascular disease. Arterioscler Thromb Vasc Biol, 25 (2005), pp. 29-38.

4. D. Siegel-Axel, K. Daub, P. Seizer, S. Lindemann, M. Gawaz. Platelet lipoprotein interplay: trigger of foam cell formation and driver of atherosclerosis. Cardiovasc Res, 78 (2008), pp. 8-17.

5. A.E. May, P. Seizer, M. Gawaz. Platelets: inflammatory firebugs of vascular walls. Arterioscler Thromb Vasc Biol, 28 (2008), pp. s5-s10.

6. S. Massberg, K. Brand, S. Gruner, S. Page, E. Muller, I. Muller, et al. A critical role of platelet adhesion in the initiation of atherosclerotic lesion formation. J Exp Med, 196 (2002), pp. 887-896.

7. M. Gawaz, H. Langer, A.E. May. Platelets in inflammation and atherogenesis. J Clin Invest, 115 (2005), pp. 33783384.

8. S. Badrnya, W.C. Schrottmaier, J.B. Kral, K.C. Yaiw, I. Volf, G. Schabbauer, et al. Platelets mediate oxidized lowdensity lipoprotein-induced monocyte extravasation and foam cell formation. Arterioscler Thromb Vasc Biol, 34 (2014), pp. 571-580.

9. S. Pitsilos, J. Hunt, E.R. Mohler, A.M. Prabhakar, M. Poncz, J. Dawicki, et al. Platelet factor 4 localization in carotid atherosclerotic plaques: correlation with clinical parameters. Thromb Haemost, 90 (2003), pp. 11121120.

10. J.A. Coppinger, G. Cagney, S. Toomey, T. Kislinger, O. Belton, J.P. McRedmond, et al. Characterization of the proteins released from activated platelets leads to localization of novel platelet proteins in human atherosclerotic lesions. Blood, 103 (2004), pp. 2096-2104

11. Yilmaz, B. Lipfert, I. Cicha, K. Schubert, M. Klein, D. Raithel, et al. Accumulation of immune cells and high expression of chemokines/chemokine receptors in the upstream shoulder of atherosclerotic carotid plaques. Exp Mol Pathol, 82 (2007), pp. 245-255.

12. P. Libby, P.M. Ridker, G.K. Hansson, Leducq. Transatlantic Network on A Inflammation in atherosclerosis: from pathophysiology to practice. J Am Coll Cardiol, 54 (2009), pp. 2129-2138.

13. S.L. Stephen, K. Freestone, S. Dunn, M.W. Twigg, S. Homer-Vanniasinkam, J.H. Walker, et al. Scavenger receptors and their potential as therapeutic targets in the treatment of cardiovascular disease. Int J Hypertens (2010), p. 646929.

14. H.C. Stary, A.B. Chandler, S. Glagov, J.R. Guyton, W. Insull Jr., M.E. Rosenfeld, et al. A definition of initial, fatty streak, and intermediate lesions of atherosclerosis. A report from the Committee on Vascular Lesions of the Council on Arteriosclerosis, American Heart Association. Circulation, 89 (1994), pp. 2462-2478.

15. Tedgui, Z. Mallat. Cytokines in atherosclerosis: pathogenic and regulatory pathways. Physiol Rev, 86 (2006), pp. 515-581.

16. J.P. Sluijter, W.P. Pulskens, A.H. Schoneveld, E. Velema, C.F. Strijder, F. Moll, et al. Matrix metalloproteinase 2 is associated with stable and matrix metalloproteinases 8 and 9 with vulnerable carotid atherosclerotic lesions: a study in human endarterectomy specimen pointing to a role for different extracellular matrix metalloproteinase inducer glycosylation forms. Stroke, 37 (2006), pp. 235-239. 
17. C. Schulz, S. Massberg. Platelets in atherosclerosis and thrombosis. Handb Exp Pharmacol (2012), pp. 111-133.

18. B.A. Wasserman, R.J. Wityk, H.H. Trout III, R. Virmani. Low-grade carotid stenosis: looking beyond the lumen with MRI. Stroke, 36 (2005), pp. 2504-2513.

19. T. Saam, T.S. Hatsukami, N. Takaya, B. Chu, H. Underhill, W.S. Kerwin, et al. The vulnerable, or high-risk, atherosclerotic plaque: noninvasive MR imaging for characterization and assessment. Radiology, 244 (2007), pp. 64-77.

20. J. Klostergaard, C.E. Seeney. Magnetic nanovectors for drug delivery. Nanomedicine, 8 (Suppl. 1) (2012), pp. S37-S50.

21. H.S. Choi, J.V. Frangioni. Nanoparticles for biomedical imaging: fundamentals of clinical translation. Mol Imaging, 9 (2010), pp. 291-310.

22. M.J. Jacobin, J. Laroche-Traineau, M. Little, A. Keller, K. Peter, M. Welschof, et al. Human IgG monoclonal antialpha(Ilb)beta(3)-binding fragments derived from immunized donors using phage display. J Immunol, 168 (2002), pp. 2035-2045.

23. S. Mornet, J. Portier, E. Duguet. A method for synthesis and functionalisation of ultrasmall superparamagnetic covalent carriers based on maghemite and dextran. J Magn Magn Mater, 293 (2005), pp. 127-134.

24. P.A. Kitts, R.D. Possee. A method for producing recombinant baculovirus expression vectors at high frequency. Biotechniques, 14 (1993), pp. 810-817.

25. V.A. Luckow, S.C. Lee, G.F. Barry, P.O. Olins. Efficient generation of infectious recombinant baculoviruses by site-specific transposon-mediated insertion of foreign genes into a baculovirus genome propagated in Escherichia coli. J Virol, 67 (1993), pp. 4566-4579.

26. S. Juliant, M. Leveque, P. Cerutti, A. Ozil, S. Choblet, M.L. Violet, et al. Engineering the baculovirus genome to produce galactosylated antibodies in lepidopteran cells. Methods Mol Biol, 988 (2013), pp. 59-77.

27. R. Robert, G. Clofent-Sanchez, A. Hocquellet, M.J. Jacobin-Valat, D. Daret, A.M. Noubhani, et al. Large-scale production, bacterial localization assessment and immobilized metal affinity chromatography purification of a human single-chain Fv antibody against alphallb-beta3 integrin. Int J Biol Macromol, 39 (2006), pp. 51-59.

28. M.J. Jacobin-Valat, K. Deramchia, S. Mornet, C.E. Hagemeyer, S. Bonetto, R. Robert, et al. MRI of inducible Pselectin expression in human activated platelets involved in the early stages of atherosclerosis. NMR Biomed, 24 (2011), pp. 413-424.

29. F. Sonvico, S. Mornet, S. Vasseur, C. Dubernet, D. Jaillard, J. Degrouard, et al. Folate-conjugated iron oxide nanoparticles for solid tumor targeting as potential specific magnetic hyperthermia mediators: synthesis, physicochemical characterization, and in vitro experiments. Bioconjug Chem, 16 (2005), pp. 1181-1188.

30. D. Pidard, R.R. Montgomery, J.S. Bennett, T.J. Kunicki. Interaction of AP-2, a monoclonal antibody specific for the human platelet glycoprotein Ilb-IIla complex, with intact platelets. J Biol Chem, 258 (1983), pp. 1258212586.

31. S.J. Shattil, J.A. Hoxie, M. Cunningham, L.F. Brass. Changes in the platelet membrane glycoprotein IIb.Illa complex during platelet activation. J Biol Chem, 260 (1985), pp. 11107-11114.

32. G. Niccoli, G.G. Stefanini, D. Capodanno, F. Crea, J.A. Ambrose, R. Berg. Are the culprit lesions severely stenotic? JACC Cardiovasc Imaging, 6 (2013), pp. 1108-1114.

33. G.W. Stone, A. Maehara, A.J. Lansky, B. de Bruyne, E. Cristea, G.S. Mintz, et al. A prospective natural-history study of coronary atherosclerosis. N Engl J Med, 364 (2011), pp. 226-235.

34. S. Lajus, G. Clofent-Sanchez, C. Jais, P. Coste, P. Nurden, A. Nurden. Thrombocytopenia after abciximab use results from different mechanisms. Thromb Haemost, 103 (2010), pp. 651-661.

35. O.J. McCarty, R.B. Conley, W. Shentu, G.W. Tormoen, D. Zha, A. Xie, et al. Molecular imaging of activated von Willebrand factor to detect high-risk atherosclerotic phenotype. JACC Cardiovasc Imaging, 3 (2010), pp. 947955.

36. O. Postea, E.M. Vasina, S. Cauwenberghs, D. Projahn, E.A. Liehn, D. Lievens, et al. Contribution of platelet CX(3)CR1 to platelet-monocyte complex formation and vascular recruitment during hyperlipidemia. Arterioscler Thromb Vasc Biol, 32 (2012), pp. 1186-1193.

37. F.S. Czepluch, H. Kuschicke, C. Dellas, J. Riggert, G. Hasenfuss, K. Schafer. Increased proatherogenic monocyteplatelet cross-talk in monocyte subpopulations of patients with stable coronary artery disease. J Intern Med, 275 (2014), pp. 144-154. 
38. N. Li. CD4 + T cells in atherosclerosis: regulation by platelets. Thromb Haemost, 109 (2013), pp. 980-990.

39. A.B. Chandler, R.A. Hand. Phagocytized platelets: a source of lipids in human thrombi and atherosclerotic plaques. Science, 134 (1961), pp. 946-947.

40. G.R. De Meyer, D.M. De Cleen, S. Cooper, M.W. Knaapen, D.M. Jans, W. Martinet, et al. Platelet phagocytosis and processing of beta-amyloid precursor protein as a mechanism of macrophage activation in atherosclerosis. Circ Res, 90 (2002), pp. 1197-1204.

41. K. Daub, P. Seizer, K. Stellos, B.F. Kramer, B. Bigalke, M. Schaller, et al. Oxidized LDL-activated platelets induce vascular inflammation. Semin Thromb Hemost, 36 (2010), pp. 146-156.

42. C. Foresta, G. Strapazzon, L. De Toni, F. Fabris, F. Grego, G. Gerosa, et al. Platelets express and release osteocalcin and co-localize in human calcified atherosclerotic plaques. J Thromb Haemost, 11 (2013), pp. 357365.

43. P. Seizer, T. Schonberger, M. Schott, M.R. Lang, H.F. Langer, B. Bigalke, et al. EMMPRIN and its ligand cyclophilin A regulate MT1-MMP, MMP-9 and M-CSF during foam cell formation. Atherosclerosis, 209 (2010), pp. 51-57.

44. G.W. van Lammeren, G. Pasterkamp, J.P. de Vries, L. Bosch, J.J. de Haan, D.P. de Kleijn, et al. Platelets enter atherosclerotic plaque via intraplaque microvascular leakage and intraplaque hemorrhage: a histopathological study in carotid plaques. Atherosclerosis, 222 (2012), pp. 355-359.

45. T.S. Hatsukami, C. Yuan. MRI in the early identification and classification of high-risk atherosclerotic carotid plaques. Imaging Med, 2 (2010), pp. 63-75.

46. P.K. Cheruvu, A.V. Finn, C. Gardner, J. Caplan, J. Goldstein, G.W. Stone, et al. Frequency and distribution of thincap fibroatheroma and ruptured plaques in human coronary arteries: a pathologic study. J Am Coll Cardiol, 50 (2007), pp. 940-949.

47. A.K. Pavlou, J.M. Reichert. Recombinant protein therapeutics-success rates, market trends and values to 2010. Nat Biotechnol, 22 (2004), pp. 1513-1519.

48. J.M. Reichert. Antibodies to watch in 2014. MAbs, 6 (2014), pp. 5-14.

49. P. Stas, I. Lasters. Immunogenicity of therapeutic antibodies. Med Sci (Paris), 25 (2009), pp. 1070-1077.

50. A.C. Chan, P.J. Carter. Therapeutic antibodies for autoimmunity and inflammation. Nat Rev Immunol, 10 (2010), pp. 301-316. 


\section{Supplementary material}

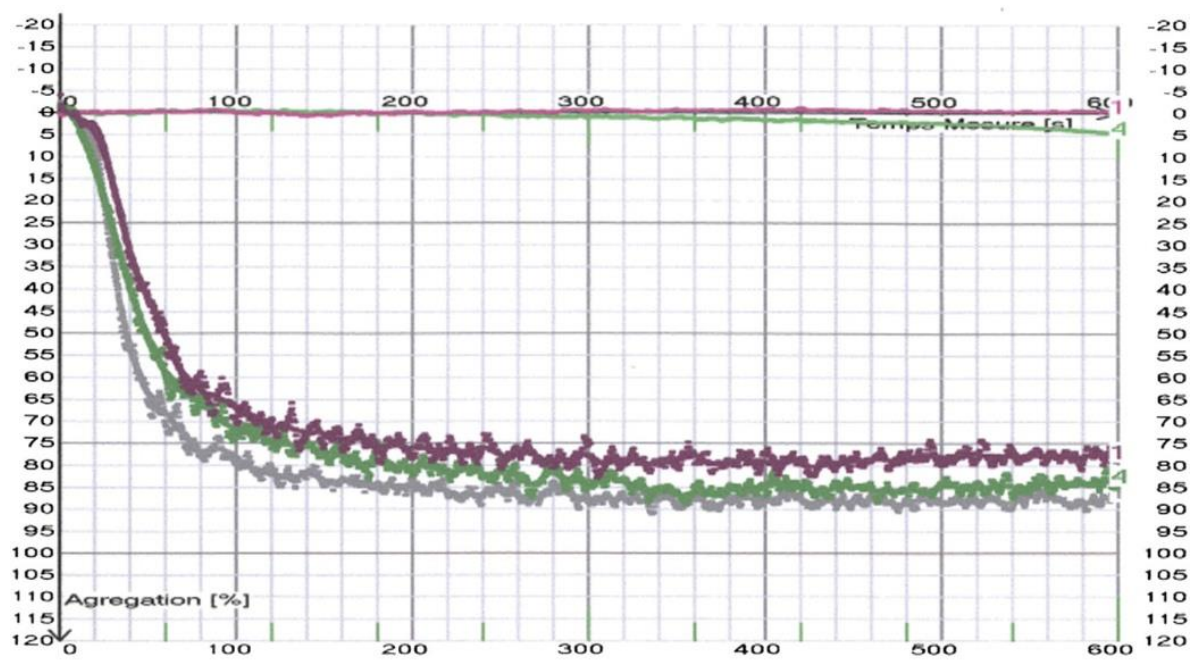

\begin{tabular}{|c|c|}
\hline TRAP-6 $10 \mu \mathrm{M}$ & PRP \\
\hline 0 & TEG4 IgG4 $25 \mu \mathrm{g}$ \\
\hline 0 & TEG4 IgG4 50 $\mathrm{\mu g}$ \\
\hline TRAP-6 10 $\mu \mathrm{M}$ & TEG4 IgG4 25 $\mathrm{\mu g}$ \\
\hline TRAP-6 10 $\mu \mathrm{M}$ & 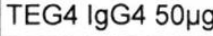 \\
\hline
\end{tabular}

Figure S1. Aggregometry experiments.

Recombinant IgG4 TEG4 antibody was tested on human platelet-rich plasma (PRP) to evaluate its potential action on platelet properties. Experiments without platelet activator were performed with $25 \mu \mathrm{g}$ (light green curve) and $50 \mu \mathrm{g}$ (pink curve) antibody and showed no TEG4-induced aggregation. In the presence of $10 \mu M$ of the platelet activator TRAP (thrombin receptor activating peptide), $25 \mu \mathrm{g}$ (green curve) and $50 \mu \mathrm{g}$ (purple curve) of rIgG4 TEG4 antibody shows no inhibitory effect. The grey curve shows the effect of TRAP on platelets without the antibody. 
Hum an activated plate lets
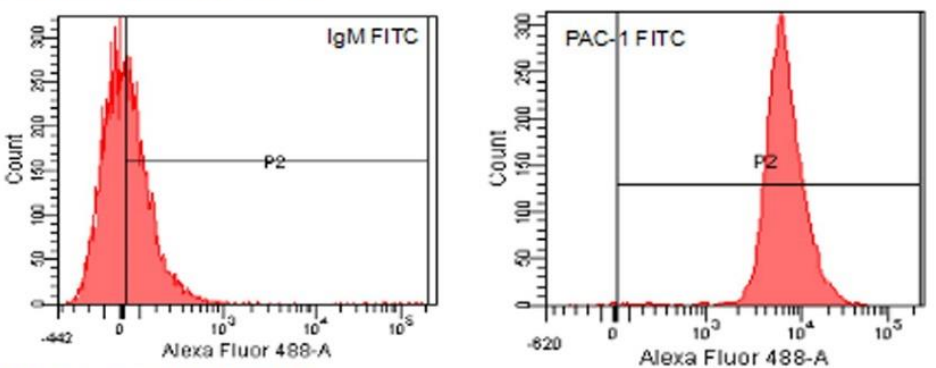

Mouse activated plate lets
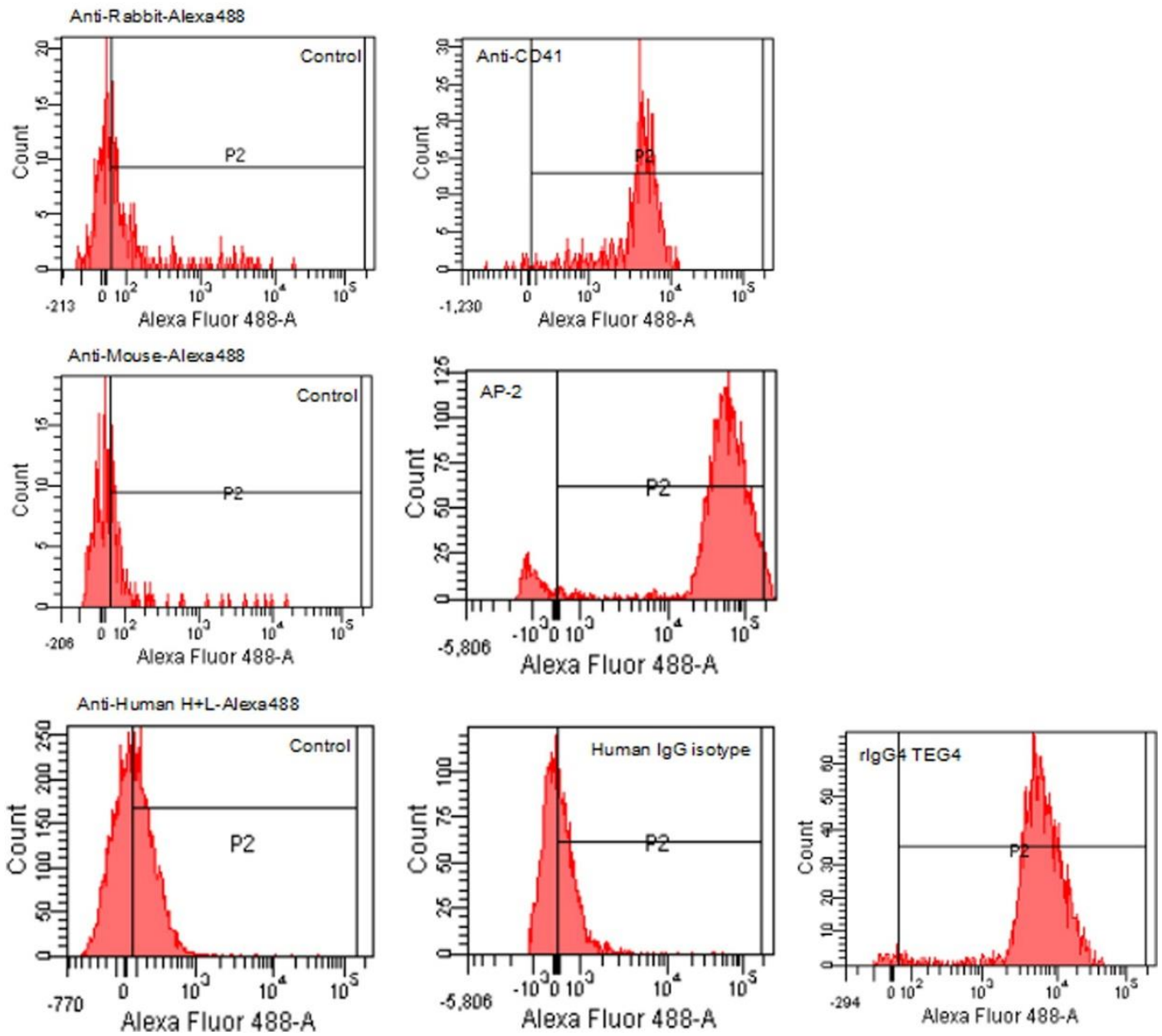

Figure S2. Flow cytometry on human and mouse activated platelets.

Upper panels: labelling of human activated platelets.

Incubation of human activated platelets with PAC-1 FITC antibody targeting human $\alpha I I b \beta 3$ or FITC-labelled isotypic control.

Other panels: labelling of mouse activated platelets.

Incubation of murine activated platelets with commercially available rabbit anti-CD41 monoclonal antibody, AP-2 murine monoclonal antibody or rIgG4 TEG4 human antibody was followed by a second incubation with species-specific secondary antibodies labelled with Alexa Fluor 488. For rIgG4 TEG4, an isotypic control was used. 


\section{Wild-type (C57BL-6J) mouse}

Anti-Human $\mathrm{H}+\mathrm{L}$

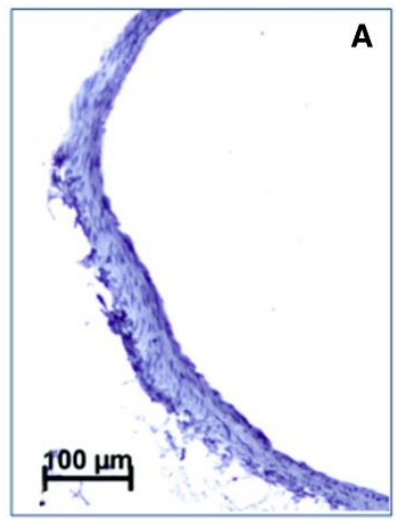

IgG cont-VUSPIO

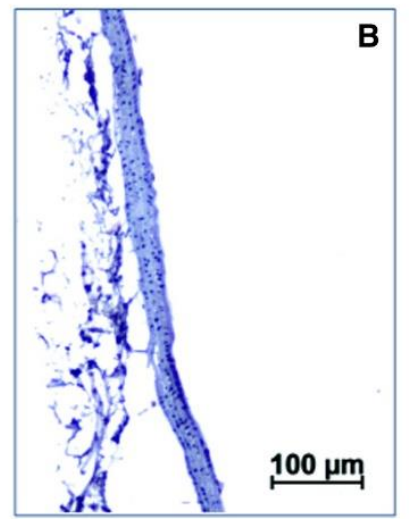

TEG4-VUSPIO

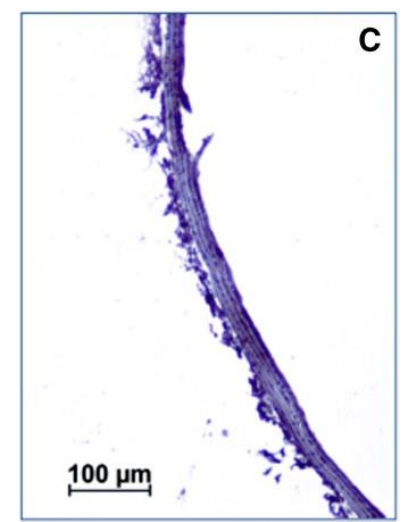

Figure S3. Immunohistochemical experiment on arterial sections from wild-type C57BL/6J mice. The conjugates TEG4VUSPIO and IgG cont-VUSPIO were tested on sections of wild-type C57BL/6J mice which did not develop atherosclerosis $(\boldsymbol{C}$, B). A control was performed with a secondary HRP-labelled anti-human $H+L$ antibody $(\boldsymbol{A})$. Bar: $100 \mu \mathrm{m}$. 